\title{
The Effects of A Combined Exercise, Healthy Diet, and Dental Hygiene Program on Body Composition, Physical Condition, Eating Habits, and Dental Care for Shelter Home Residents with Intellectual Disabilities
}

\section{Tse MMY ${ }^{*}$, Vong SKS ${ }^{1}$, Heung $\mathrm{R}^{1}$ and Lam YLA ${ }^{2}$}

${ }^{1}$ School of Nursing, The Hong Kong Polytechnic University, Hong Kong SAR

${ }^{2}$ Shelter Workshop cum Hostel, Pentecostal Church of Hong Kong, Hong Kong SAR

${ }^{*}$ Corresponding author: Tse MMY, Assistant Professor, School of Nursing, The Hong Kong Polytechnic University, Hong Kong SAR, E-mail: mimi.tse@polyu.edu.hk

Citation: Tse MMY, Vong SKS, Heung R, Lam YLA (2014) The Effects of A Combined Exercise, Healthy

Diet, and Dental Hygiene Program on Body Composition, Physical Condition, Eating Habits, and

Dental Care for Shelter Home Residents with Intellectual Disabilities. J Nutr Health Sci 1(3): 303. doi:

$10.15744 / 2393-9060.1 .303$

Received Date: June 18, 2014 Accepted Date: November 03, 2014 Published Date: November 06, 2014

\begin{abstract}
Background: Physical inactivity, poor diet habit, and poor dental hygiene are big concerns among people with intellectual disabilities that cause a rise in obesity rates with increases in the risk of chronic diseases as well as emotional problems. A healthy diet and regular physical activity can prevent chronic diseases. Proper oral hygiene may improve a person's health and quality of life. Yet, the effects of physical activity, healthy diet and oral care programs on people with intellectual disabilities who live in shelter homes are lack. The present study investigated the influence of a program integrating physical activity, a healthy diet, and dental hygiene on the physical functions, body composition, exercise and dietary habits, and oral care of a group of adults with intellectual disabilities living in a shelter home.

Methods: Residents living in a shelter home (27 males and 24 females) participated in a 10-month integrated program consisted of a series of physical activity, healthy diets, and dental hygiene regime delivered by nurse and physiotherapist. Body composition, physical functions, changes in exercise and eating habits and dental hygiene were measured before and after the program.

Results: After the program the participants showed a trend of improvement on physical functions on the Timed Up and Go test, Sit to Stand, single leg standing and Berg Balance Scale. Moreover, they tended to exercise for a longer duration and performed more than one type of exercise. The skills on brushing teeth were significantly improved and more participants acquired correct dental knowledge. However, no significant improvements on the body composition and eating habit.

Conclusion: The present program integrating physical exercise, a healthy diet, and dental hygiene led some clinical improvement in physical function and exercise habit after the program for people with intellectual disabilities living in a shelter home. Moreover, improvements were seen in their skill in brushing their teeth and in their dental knowledge. No significant change was seen in their body composition and eating habits.
\end{abstract}

Keywords: Physical activity; Healthy diet; Dental hygiene; Intellectual disabilities; Shelter home

\section{Introduction}

It has been documented that the physical fitness of adults with intellectual disabilities is less optimal than that of people without intellectual disabilities [1]. The prevalence of physical inactivity, poor diets, and obesity among people with intellectual disabilities is high [2].This may be attributed to their sedentary lifestyle, and associated with their health and mental condition. Temple and Walkley have reported that a low motivation to participate in physical activities, inadequate social support, unclear policies, and a lack of financial support are major factors inhibiting engagement in physical activities by people with intellectual disabilities [3]. Therefore, over time, their level of physical fitness and capacity to exercise will decrease. As a consequence, obesity rates will rise among this population, with resulting increases in the risk of developing diabetes, hypertension, cardiovascular disease, stroke, and other chronic diseases.

Physical activity has been proven to have a positive influence on physical outcomes and fitness in different populations. The evidence shows that regular physical activity is important to prevent obesity and to reduce the burden of chronic diseases. Moreover, an increasing number of studies have found that physical activity can make people feel good, enhance their sense of self-esteem, have a positive effect on emotional well-being [4,5], and be a potentially effective strategy for managing depression and anxiety [6]. 
Increasing the level of moderate to vigorous exercise is one of the most effective ways of improving the health of people with intellectual disabilities. Elmahgoub et al. conducted an exercise intervention that combined strengthening and aerobic endurance exercises for overweight and obese adolescents with intellectual disabilities [1]. The results showed that the intervention led to a significant decrease in the body mass index, waist circumference, and fat mass of the participants. Lipid levels also decreased significantly. Moreover, improvements in their physical fitness were seen in terms of their muscle strength and in their results in the sit to stand test and 6-minute walking test. However, evidence is lacking of the effects of physical activity programs on people with intellectual disabilities who live in shelter homes. They often lack knowledge of how to get adequate exercise. Their perseverance and confidence in exercising is also weak.

Besides physical inactivity, residents in shelter homes were observed to consume unhealthy snacks or to have an unhealthy diet [7]. They might not have a clear concept of which foods are healthful. They may also have less control over their diet [8]. Diet has a strong influence on the development and progression of the most common chronic illnesses, including cardiovascular disease, dementia, diabetes, and cancer [9]. The Global Strategy for Diet and Physical Activity for Health [10] suggests that member states of the World Health Organization (WHO), United Nations agencies, civil society, and the private sector can help to reduce the occurrence of non-communicable diseases by increasing levels of physical activity and improving diets for both children and adults.

Dental hygiene is another important health concern for residents living in shelter homes. There is evidence that the oral hygiene of people with intellectual disabilities is poor [11]. Their oral health may be neglected because of their disability, or because they may have limited access to oral health care. It has been reported that "dental treatment is the greatest unattended health need of the disabled," and having less education, a lower IQ, and a low income are the most important predictors of poor oral hygiene and periodontal status [12]. Poor teeth could lead to difficulties with eating, which could affect a person's health and emotional state. Therefore, the promotion of dental hygiene is important.

A healthy diet and regular physical activity are key components in the prevention of chronic diseases and in the treatment of physical inactivity. Proper oral hygiene may improve a person's health and quality of life. The goals of the present study were to investigate the influence of a program integrating physical activity, a healthy diet, and dental hygiene on the physical functions, body composition, exercise and dietary habits, and oral care regime of a group of adults with intellectual disabilities living in a shelter home.

\section{Methods}

\section{Participants}

All of the residents living in a shelter home were invited to participate in this study ( $\mathrm{n}=55,28$ males and 27 females). They had been diagnosed with an intellectual disability by a psychiatric doctor. All were receiving regular check-ups at a public hospital. Psychiatrically unstable people were excluded from this study. Those in very poor health, such as those who had been bedridden for a prolonged period or who were suffering from organ failure were also excluded. Finally, 51 of the residents ( 27 males and 24 females) with psychiatrically stable participated in the study. All of the participants were fully informed of the procedures of this study, along with its possible risks and discomfort by the researcher. The staff and person in charge of the shelter home were also informed about the details of the program and were asked to encourage the participants to become actively involved in the program. Written voluntary consent was obtained from the participants before the start of the program. For those participants with difficulty in reading the consent or did not understand the details of the study, verbal explanation were given and verbal consents were obtained before the study. The experimental protocol was approved by The Hong Kong Polytechnic University.

\section{Program}

The integrated program consisted of a series of educational talks and practical sessions on physical activities, healthy diets and lifestyles, and dental hygiene, carried out in the shelter home for 10 months. Ten 90-minute sessions on healthy diets and physical exercise program were conducted each month. Four sessions on dental hygiene were delivered over two months. The sessions were run by the research team, consisting of a registered nurse, nursing students, and a registered physiotherapist.

The healthy diets program was delivered by a registered nurse, who introduced educational talks on the function of food, types of nutrition, and information on the nutrition of commonly eaten foods and snacks, and explained what and how important a food pyramid is. To encourage the participants to become actively involved, the education talks contained a PowerPoint presentation with many pictures, videos, interactive games and activities, and Question\& Answer sessions. The staffs in the shelter home was encouraged to join the talks, and were given suggestions on how to prepare more healthful meals for the residents.

The physical exercise program that was designed and supervised by a physiotherapist, a nurse, and nursing students. First, in a brief presentation with many pictures by the physiotherapist explained the importance of engaging in physical exercise, and introduced the types of exercise and their effects. Then, all of the participants were encouraged to perform exercises as a group in 
the function room of the shelter home. The exercise program started with a warm-up, followed by stretching exercises involving the head, neck and shoulders, upper and lower back, and upper and lower limbs. A 5-minute break was given, followed by aerobic exercises. According to their physical capacity and progress in learning, the residents practiced gentle aerobic steps with music (basic marching, with steps coordinating the upper and lower limbs). The aerobic exercises began with 10 minutes during the first session and progressed to 30 minutes in the last session. The physiotherapist monitored the physical and learning capacity of each participant and modified the frequency, intensity, and speed of the aerobic exercises. The nurse and students monitored the safety and the physical condition of the participants during the practical session. They provided individual help to each participant when he or she showed difficulty in following the exercises. To enhance the residents' excitement and interest in taking part in the physical activities, interactive physical games were delivered by the nurse and assistants. The participants were separated into groups and joined in a competition involving kicking balls, throwing beanbags, and engaging in brisk walking exercises. The nurse and students monitored the safety and the physical condition of the participants during the games. Before the end of each session, each participant rode on a stationary bicycle or leg ergometer for 5 to 10 minutes. The participants were able to control the bike or ergometer to proceed at their own speed. During the exercise, the nurse and the students monitored the safety and the physical condition of the participants.

Besides the supervised exercise program, the participants were encouraged to perform exercises on their own time. They were given an exercise pamphlet containing pictures and instructions on what had been practiced during the supervised practical exercises. A stationary bicycle and leg ergometer were provided for their daily use, and the participants using them were monitored by the staff. The participants were encouraged to record their exercises every week.

In the dental hygiene program the registered nurse and nursing students provided interactive talks on the function of the teeth, common dental problems, and demonstrated how to brush one's teeth and use dental tools to prevent and reduce dental problems. The participants practiced the correct steps of brushing teeth during practical sessions.

\section{Outcome Measures}

Body composition: Body Mass Index (BMI), the circumference of waist and hip, and the waist-hip ratio (WHR) were measured before and after the exercise program. BMI is defined as the individual's body mass divided by the square of the individual's height with the unit $\mathrm{kg} / \mathrm{m}^{2}$. BMI is used to measure the size and composition of the body, and to diagnose whether an individual is underweight or overweight. The Hospital Authority of Hong Kong has categorized a BMI ranging from 18.5 to 22.9 as normal, less than 18.5 as underweight, between 23.0 and 24.9 as overweight, and 25.0 or above as obese[13]. The waist circumference was measured at the smallest circumference of the waist around the umbilicus [14]. The hip circumference was measured at the widest part of the buttocks, with the tape parallel to the floor [15]. The WHR (i.e., the waist circumference divided by the hip circumference) is an additional measure of the distribution of body fat. It is an indicator of the health of a person, of the person's risk of developing a serious health condition, and a measurement of obesity. A WHR of greater than 0.9 for males and greater than 0.85 for females is an indication of abdominal obesity. A greater WHR is associated with an increased risk of myocardial infarction, stroke, and premature death [15].

Physical functions: The participants were tested using the Timed Up and Go test (TUG), single leg stand test, Sit to Stand Test, Berg Balance Scale (BBS), and Walking Speed before and after the exercise program. The TUG was originally developed to measure the mobility skills of frail community-dwelling elderly people and to predict their risk of falling [16]. It measures the time it takes a subject to stand up from an armchair, walk a distance of 3 meters, turn, walk back to the armchair, and sit down. The reliability of the test has been reported to be high, with a sensitivity and specificity of $87 \%$ for people of fall. In the single leg stand test, the participants were instructed to stand in a comfortable position with their eyes open and their arms by the side of their body, and then to stand unassisted on one leg. They were timed in seconds from the time that they lifted one foot from the floor to when that foot touched the ground or when they lost their balance [17]. In the Sit to Stand test, the participants were asked to raise a chair 5 times. This test has been used for multiple purposes, including as an indicator of lower limb strength, disability, postural control, and the risk of falling [18]. The BBS was developed to measure balance. It consists of 14 items on a scale of 0 to 4 . A score of 0 is given if the subject is unable to do the task, and a score of 4 is given if the subject is able to complete the task based on the criterion for each item. The maximum total score is 56 . The items include mobility tasks (e.g., sitting/ standing unsupported, transferring, sit to stand test) and more difficult balance tasks (e.g., turning, tandem standing, single leg stance). Values indicating high reliability and validity have been reported mainly on elderly people. A cutoff score of 45 on the BBS is relatively good for identifying people who are not at-risk of falling (specificity $=90 \%$ ) [16]. Walking speed was measured by the time it took the participants to walk 8 meters. The time it took them to get to the middle- 4 meters was recorded.

Changes in exercise and eating habits: The exercise and eating habits were measured before and after the program. The questionnaire for measuring exercise was designed by a physiotherapist. The self-perceived benefit of engaging in exercise was measured in 3-point Likert scale from yes, neutral to no. The frequency of doing exercise was asked in ordinal scale from every day, 3 times a week, 2 times a week, occasionally to no exercise. The duration of doing exercise was recorded in minutes. The type of exercise the participants performed was also recorded. 
The participants' eating habits were measured with a self-designed questionnaire designed by a nutritionist. Their habits on having breakfast, lunch, and dinner were measured in nominal scale. The quantity of food, e.g. rice, meat, eggs, vegetables, fruit, water, and snacks that they consumed were measured in ordinal scales. The tastes of the food that they liked were measured in 5-point Likert scale from "like very much" to "do not like very much".

\section{Program attendance and Exercise compliance}

The number of participants attended on each program session was marked by the nursing students. The time of doing the exercise that were learnt at the practical sessions (the aerobic exercise, stationary bicycle and leg ergometer) on their own time was recorded by the shelter staff. The participants with overweighed and obesity were only recorded due to the limits of manpower and limited numbers of equipment. Number of days and the total exercise minutes in a week were measured at the mid-point of the program and at the end of the program.

\section{Dental hygiene}

A self-designed dental hygiene questionnaire was used to measure the participants' knowledge of dental hygiene before and after the program. The questionnaire was divided into two parts: in the first part the participants were asked to record the steps they took in brushing their teeth, with a total of 12steps [19]. In the second part the participants were asked about the function of the teeth, and about common dental problems and their causes.

Besides of the objective measures, a group sharing session was held in the shelter home at the end of the program. The participants were invited to share their feelings about the program, and gave feedbacks voluntarily. The staff made the records.

\section{Statistics}

A statistical analysis was carried out using the Statistical Package for the Social Sciences version 20 (SPSS InC, Chicago, IL, USA). Descriptive statistics (mean, standard deviation) and frequency were used to measure the baseline characteristics of the participants. A paired samples t-test was used to examine differences in outcomes before and after the program.

\section{Results}

Table 1 shows the demographic data of the participants. The majority of the participants had a mild to moderate grade of intellectual disabilities. About $67 \%$ of the participants were able to walk independently, and $26 \%$ walked indoors with walking aids. More than half of the participants (56\%) were classified as obese or overweight according to the Hong Kong BMI classification. The WHR was 0.88 for all participants and 0.89 for those who were overweight or obese.

\begin{tabular}{|c|c|c|c|}
\hline & $\mathbf{N}$ & $\%$ & Mean \pm S.D. \\
\hline Age (years old) & & & $45.10 \pm 10.93$ \\
\hline \multicolumn{4}{|l|}{ Gender } \\
\hline Male & 27 & $(52.9)$ & \\
\hline Female & 24 & $(47.1)$ & \\
\hline \multicolumn{4}{|l|}{ Level of MR } \\
\hline Mild & 17 & $(33.3)$ & \\
\hline Moderate & 33 & $(64.7)$ & \\
\hline Severe & 1 & $(2.0)$ & \\
\hline \multicolumn{4}{|l|}{ Level of Mobility } \\
\hline Wheelchair bound & 2 & $(3.9)$ & \\
\hline Walks indoor with walking aids & 21 & $(41.2)$ & \\
\hline Walks independently & 28 & $(54.9)$ & \\
\hline \multicolumn{4}{|l|}{ Acute disease in the recent 3 months } \\
\hline Yes & 8 & $(15.7)$ & \\
\hline No & 43 & $(84.3)$ & \\
\hline Years in shelter home & & & $13.39 \pm 7.68$ \\
\hline BMI & & & $24.28 \pm 4.98$ \\
\hline Normal (BMI 18.5-22.9) & 13 & $(25.5)$ & \\
\hline Overweight (BMI 23.0-24.9) & 10 & $(19.6)$ & \\
\hline
\end{tabular}




\begin{tabular}{|c|c|c|c|}
\hline & $\mathbf{N}$ & $\%$ & Mean \pm S.D. \\
\hline Obese (BMI >25) & 20 & $(39.2)$ & \\
\hline Underweight $(\mathrm{BMI}<18.5)$ & 8 & (15.7) & \\
\hline \multicolumn{4}{|l|}{ Body weight } \\
\hline Body weight at present & & & $57.31 \pm 11.43$ \\
\hline Body weight 3 months ago & & & $58.14 \pm 11.49$ \\
\hline Body weight 6 months ago & & & $59.43 \pm 11.37$ \\
\hline Waist circumference & & & $83.44 \pm 9.33$ \\
\hline Hip circumference & & & $94.84 \pm 9.18$ \\
\hline Waist-hip ratio & & & $0.88 \pm 0.06$ \\
\hline \multicolumn{4}{|l|}{ Health condition } \\
\hline Heart rate & & & $75.84 \pm 12.03$ \\
\hline Systolic Blood Pressure & & & $110.43 \pm 14.79$ \\
\hline Diastolic Blood Pressure & & & $75.27 \pm 12.24$ \\
\hline \multicolumn{4}{|l|}{ Diseases } \\
\hline Hypertension & 1 & $(2.0)$ & \\
\hline Diabetes & 1 & $(2.0)$ & \\
\hline Gout & 2 & (3.9) & \\
\hline Others & 33 & $(64.7)$ & \\
\hline More than 1 disease & 10 & $(19.6)$ & \\
\hline Unknown & 4 & (7.8) & \\
\hline \multicolumn{4}{|l|}{ Regular medication } \\
\hline Yes & 29 & $(56.9)$ & \\
\hline No & 23 & $(45.1)$ & \\
\hline
\end{tabular}

Table 1: Demographic characteristics $(\mathrm{N}=51)$

The program attendance was about $60.6 \%$ to $72.3 \%$. The reasons of not attending the sessions including medical check-up, hospitalization, sickness, and home leave.

The changes in the participants' body composition are shown in Table 2. For all of the participants, no significant difference was seen in the waist and hip circumference. The BMI, waist and hip circumference, and WHR of those participants who were overweight or obese were also similar before and after the program.

\begin{tabular}{|c|c|c|c|c|c|c|}
\hline & \multicolumn{4}{|c|}{ All subjects } & \multicolumn{3}{c|}{ Overweight and obese } \\
subjects \\
\hline & Pre (n=51) & Post (n=38) & $\begin{array}{c}P \\
\text { value }\end{array}$ & Pre (n=25) & Post (n=24) & \begin{tabular}{c} 
Palue \\
\hline $\begin{array}{c}\text { Waist } \\
\text { circumference }\end{array}$
\end{tabular} \\
\hline $\begin{array}{c}\text { Hip } \\
\text { circumference }\end{array}$ & $93.44 \pm 9.33$ & $86.45 \pm 10.61$ & 0.093 & $88.54 \pm 6.78$ & $90.15 \pm 10.67$ & 0.354 \\
\hline Waist-hip ratio & $0.88 \pm 0.06$ & $0.89 \pm 0.08$ & 0.242 & $0.89 \pm 0.06$ & $0.90 \pm 0.09$ & 0.632 \\
\hline Heart rate & $75.84 \pm 12.03$ & $72.14 \pm 9.95$ & 0.171 & $76.44 \pm 11.41$ & $73.50 \pm 10.05$ & 0.288 \\
\hline BMI & $24.28 \pm 4.98$ & $\begin{array}{c}\text { BW were only measured for } \\
\text { subjects who were overweight } \\
\text { or obese }\end{array}$ & $27.42 \pm 3.52$ & $27.97 \pm 3.88$ & 0.226 \\
\hline
\end{tabular}

Table 2: Changes in body composition 
As for changes in physical function, the participants spent less time for performing the TUG test and the sit to stand test, and also had a higher score on the BBS, although the results were not statistically significant (Table 3). When categorized by age, we found that the improvement in the TUG results after the program occurred mainly among young (aged 21 to 40) and middle-aged participants (aged 41 to 60). A slight improvement in the sit to stand test was seen among the middle-aged participants, while older participants (aged above 60) demonstrated a significant improvement in the single leg stand test, standing on the left leg, after the program $(\mathrm{p}=0.008)$. The results on walking speed were similar before and after the program for all of the participants or for each age subgroup.

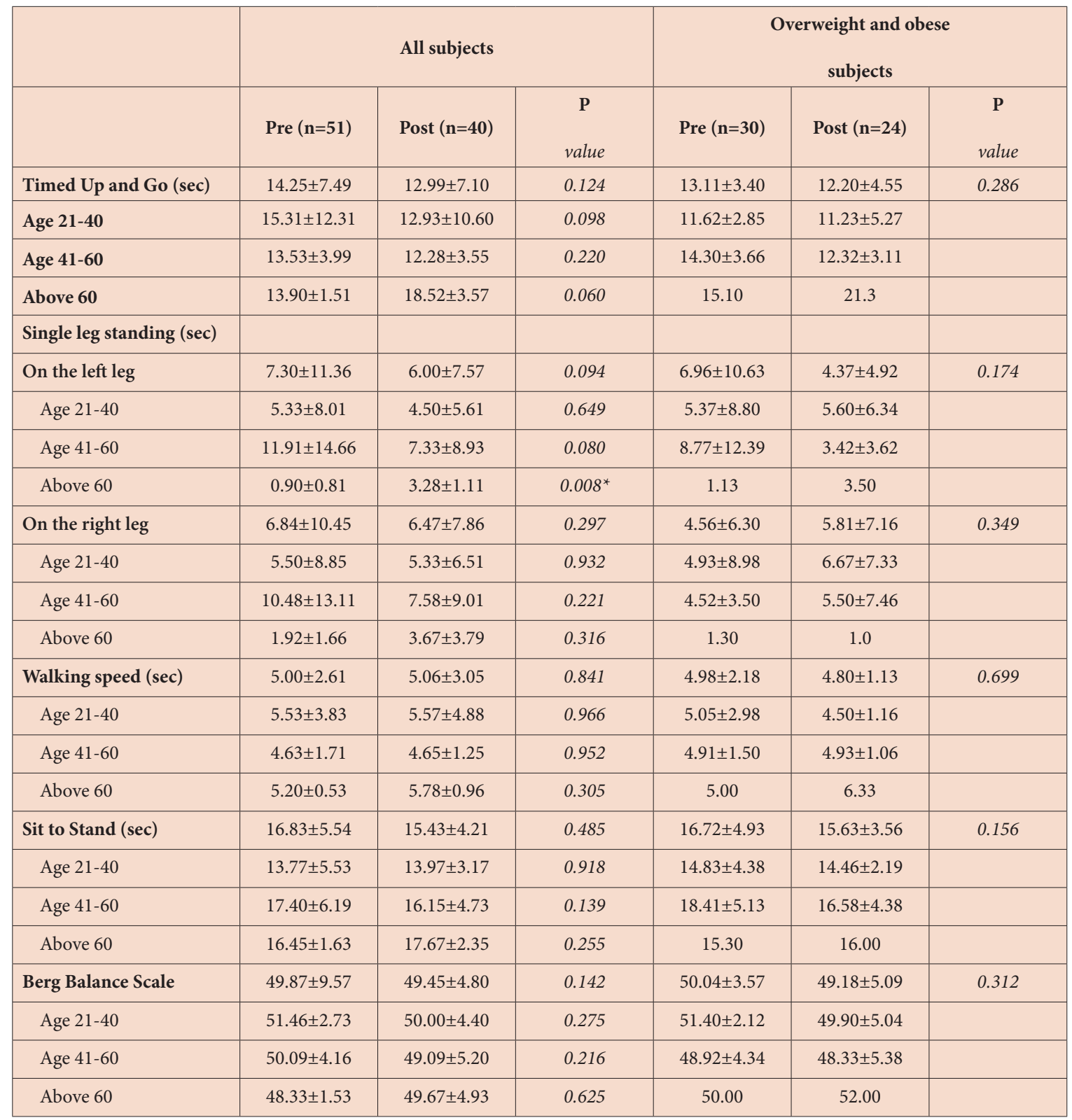

Age 21-40: $\mathrm{n}=15$; overweight and obese subjects: $\mathrm{n}=10$

Age 41-60: $n=22$; overweight and obese subjects: $n=12$

Age 60 or above: $n=3$, overweight and obese subjects: $n=1$

Table 3: Change in measures of physical function (categorized by age)

Table 4 summarizes the changes in the participants' exercise habits. More than half of the participants reported that before the program they exercised every day. After the program, a similar percentage of participants said that they exercised daily (64.7\% to $70 \%$ ). But, importantly, after the program they exercised for a longer duration during each exercise session (from $34.88 \pm 41.04$ min to $42.15 \pm 45.27 \mathrm{~min}$ ). Moreover, before the program the majority of participants performed only limb or only stretching exercises. After the program many of them performed more than one type of exercise. 


\begin{tabular}{|c|c|c|c|c|c|c|c|c|c|c|c|c|c|c|}
\hline & \multicolumn{7}{|c|}{ All subjects } & \multicolumn{7}{|c|}{ Overweight and obese subjects } \\
\hline & \multicolumn{3}{|c|}{$\operatorname{Pre}(n=51)$} & \multicolumn{3}{|c|}{ Post $(n=40)$} & \multirow{2}{*}{$\begin{array}{l}\text { Pvalue/ } \\
\text { hi } \\
\text { square }\end{array}$} & \multicolumn{3}{|c|}{$\operatorname{Pre}(n=30)$} & \multicolumn{3}{|c|}{ Post $(n=24)$} & \multirow{2}{*}{$\begin{array}{c}\text { P value/ } \\
\text { chi } \\
\text { square }\end{array}$} \\
\hline & $\mathbf{N}$ & $\%$ & Mean \pm S.D & $\mathbf{N}$ & $\%$ & Mean \pm S.D & & $\mathbf{N}$ & $\%$ & Mean \pm S.D & $\mathbf{N}$ & $\%$ & Mean \pm S.D & \\
\hline \multicolumn{15}{|l|}{ Perceived exercise benefit } \\
\hline Yes & 45 & 90.0 & & 36 & 92.3 & & & 28 & 93.3 & & 23 & 95.8 & & \\
\hline Neutral & 3 & 6.0 & & 1 & 2.6 & & & 1 & 3.3 & & 1 & 4.2 & & \\
\hline No & 2 & 4.0 & & 2 & 5.1 & & & 1 & 3.3 & & 0 & 0 & & \\
\hline \multicolumn{15}{|l|}{ Type of exercise } \\
\hline $\begin{array}{l}\text { Climbing stairs ( } 3 \text { flights } \\
\text { of stairs in shelter home) }\end{array}$ & 1 & 2.0 & & 2 & 5.0 & & & 1 & 3.3 & & 1 & 4.2 & & \\
\hline Swimming & 2 & 3.9 & & 0 & 0 & & & 1 & 3.3 & & 0 & 0 & & \\
\hline Limb exercises & 19 & 37.3 & & 5 & 12.5 & & & 13 & 43.3 & & 1 & 4.2 & & \\
\hline Stretching exercises & 5 & 9.8 & & 0 & 0 & & & 3 & 10.0 & & 0 & 0 & & \\
\hline Tai chi & 1 & 2.0 & & 0 & 0 & & & 0 & 0 & & 0 & 0 & & \\
\hline Walking & 3 & 5.8 & & 5 & 12.5 & & & 0 & 0 & & 1 & 4.2 & & \\
\hline Others & 3 & 5.8 & & 7 & 17.5 & & & 5 & 16.7 & & 5 & 20.8 & & \\
\hline More than 1 type & 11 & 21.6 & & 20 & 50.0 & & & 7 & 23.3 & & 16 & 66.6 & & \\
\hline None of exercise & 6 & 11.8 & & 1 & 2.5 & & & & & & & & & \\
\hline \multicolumn{15}{|l|}{ Exercise Frequency } \\
\hline Everyday & 33 & 64.7 & & 28 & 70.0 & & & 22 & 73.3 & & 17 & 70.8 & & \\
\hline 1 time/ week & 2 & 3.9 & & 10 & 25.0 & & & 0 & 0 & & 6 & 25.0 & & \\
\hline 2 times/ week & 5 & 9.8 & & 1 & 2.5 & & & 1 & 3.3 & & 0 & 0 & & \\
\hline 3 times/ week & 1 & 2.0 & & 0 & 0 & & & 1 & 3.3 & & 0 & 0 & & \\
\hline Occasionally & 2 & 3.9 & & 0 & 0 & & & 1 & 3.3 & & 0 & 0 & & \\
\hline Others & 1 & 2.0 & & 0 & 0 & & & 5 & 16.7 & & 1 & 4.2 & & \\
\hline No exercise & 7 & 13.7 & & 1 & 2.5 & & & & & & & & & \\
\hline $\begin{array}{l}\text { Duration of each exercise } \\
\text { session (min) }\end{array}$ & & & $34.88 \pm 41.04$ & & & $42.15 \pm 45.27$ & 0.639 & & & $37.23 \pm 49.98$ & & & $36.41 \pm 38.44$ & 0.953 \\
\hline
\end{tabular}

Table 4: Changes in exercise habits

For the exercise compliance on the learnt exercises (the aerobic exercise, stationary bicycle and leg ergometer), 17 out of 30 participants with overweighed and obesity did the exercises on their own time. At the mid-point of the program, they did those exercises $2.52 \pm 1.24$ days/week and a total of $37.50 \pm 18.24 \mathrm{~min}$ in a week. At the end of the program, they did those exercises $2.17 \pm 1.04$ days/ week and a total of $30.00 \pm 11.86 \mathrm{~min}$ in a week. No significant difference was found on the exercise day and time between the two time points $(\mathrm{p}>0.05)$.

More than $90 \%$ of the participants had breakfast, lunch, and dinner every day. They consumed about the same amount rice, meat, eggs, vegetables, milk, water and snacks before and after the program. However, after the program fewer participants reported that they liked to eat heavy tasted food (from 5.6\% to 2.5\%) or very sweet tasted food (from $20.4 \%$ to $7.5 \%$ ), and more said that they preferred to eat food that tasted "just normal."

The results on dental hygiene showed that brushing skills significantly improved after the program (from $7.25 \pm 2.7$ steps to 10.5 \pm 2.0 steps, $\mathrm{p}<0.001)$. Regarding dental knowledge, a greater percentage of participants knew about the function of teeth, dental problems, how to brush their teeth, and were willing to brush their teeth (Table 5).

At the end of the program, the participants reflected that they were happy and satisfied with the program very much. The majority of them agreed that the program enhanced their knowledge on diet, dental care and exercise. Some of the participants reported that they had no exercise habit prior to this program. One of them said that although they felted tiredness after short period of time on exercises, she would try to keep exercising. One of them reflected that she liked the exercise practical section very much. Besides of doing exercise on her own time, she also helped the staff on the exercise recording for other participants. Some of them reported that food pyramid was interesting and new for them. It was great to have practical sessions. It would be better if there were more review sessions to consolidate their knowledge. 


\begin{tabular}{|l|c|c|c|}
\hline & Pre ( $\mathrm{n}=24)$ & Post $(\mathrm{n}=24)$ & P value \\
\hline Skills in brushing teeth (full marks: 12) & $7.25 \pm 2.7$ & $10.5 \pm 2.0$ & $<0.001$ \\
\hline Knowledge & & & \\
\hline Tooth function & $30 \%$ & $40 \%$ & \\
\hline Dental problem & $28 \%$ & $40 \%$ & \\
\hline Harmful food & $24 \%$ & $26 \%$ & \\
\hline Brush teeth > 1 min & $29 \%$ & $42 \%$ & \\
\hline Brush inside and outside of the teeth & $35 \%$ & $44 \%$ & \\
\hline Like to brush teeth & $36.5 \%$ & $41.8 \%$ & \\
\hline
\end{tabular}

Table 5: Change in dental hygiene

\section{Discussion}

The present study involved conducting an integrated program of physical activities, a healthy diet and lifestyle, and dental hygiene for shelter home residents with intellectual disabilities. The participants participated in the program actively and cooperatively. This may indicate that the participants felt that physical exercise and knowledge about a healthy diet and dental hygiene was interesting and important to them. In fact, most of the physical activities that were introduced (e.g., stretching, upper and lower limb exercises, walking, riding a stationary bicycle, gentle aerobic exercises, etc.) were relatively inexpensive and could be performed by people with intellectual disabilities in the shelter home by themselves, as activities that could improve their health and physical abilities. Information on the composition of food and the food pyramid was a new concept for the participants, so that they were also highly motivation during the educational talks and interactive games. Being shown the correct method of brushing their teeth enabled the participants to have cleaner and more functional teeth for daily living. After the program, the majority of the participants indicated that they were happy and satisfied with the program.

No significant changes were noted in BMI, waist and hip circumference, and WHR after the program. This result is comparable to that of many other studies, where the BMI and waist was found to be relatively stable [20]. In Elmahgoub's study the significant decrease in BMI after the combined exercise training program may be due to the difference in the population in that study [1], which involved adolescents who might still be growing, while the participants in our study were middle-aged, old, or wheelchair bound. A different exercise training mode may be another possible explanation of the lack of significant change in our study. In our study the intensity and frequency of the exercises (gentle aerobic exercises, cycling at one's own pace, stretching and limb exercises, one supervised session per month) may not have been enough to effect a significant change due to the lower total expenditure of energy compared to a relatively intense combined exercise training mode (10 weeks of muscle strengthening and endurance exercises, 3 times a week for 50 minutes). There have been many studies investigating the effects of exercise training in obese children and adolescents with or without intellectual disabilities. The age and body composition of the participants may differ from the participants in our study, making it difficult to compare the findings of those studies with the present study.

The findings showed some clinically relevant changes in physical function in that the participants spent less time completing the TUG and Sit to stand test after the program. In addition, no deterioration was seen in many of the physical outcomes after ten months. The level of improvement was different with different age groups. Generally speaking, the program was more effective for young or middle-aged participants. In the single leg standing test, a significant improvement with the left leg and a trend of improvement with the right leg was noted among the three participants in the old-aged group. However, because of the small sample size, it will be necessary to conduct a further study with a larger sample to investigate the effect on one leg standing. No significance difference in other measures of physical function before and after the program can be attributed to the choice of outcome measures. The outcomes measured were balance and lower limb muscle strength, with good reliability and validity, in the elderly population. However, the majority of the participants in the study were reasonably mobile; only two participants were wheelchair bound. Yet their scores on the BBS before the program was $49.87 \pm 9.57$-slightly higher than the cut-off point for people with a high risk of falling [16]. It is suggested that, after the present exercise training mode, some other measures be used to address improvements or changes in aerobic capacity and exercise endurance, such as the 6-minute walking test, exercise endurance with aerobic steps, the strength of specific muscle groups, muscle fatigue resistance and heart rate, and so on [1].

It is interesting to note that over $50 \%$ of the participants were in the habit of exercising every day before the program commenced. However, the duration of exercise at each session increased slightly after the program, also the variety of exercises. This met one goal of the study, which was to boost the participants' exercise habits and improve their knowledge about exercising.

Regarding the exercise compliance on the aerobic exercise and cycling, only 57\% of the participants did. Moreover, the number of days and the total exercise duration in a week was lesser than the suggestion from WHO. The reasons of low compliance on the exercise may be due to the limits of manpower. There was no particular staff was responsible for monitoring them to do the exercise or marking their exercise record. Some of the participants might not have high motivation on doing exercise on their own. 
The results on the participants' eating habits were not promising. It is not easy to change a person's eating habits unless the participant is suddenly confronted with a serious health problem [21]. In addition, the questionnaire designed the use of ordinal scales inquiring about the quantity of food consumed, may not be sensitive enough to detect slight differences or improvements. Moreover, it is uncertain how much of the knowledge taught at the educational talks and activities can be applied in daily life. Periodic medical check-ups and regular blood tests may be better at detecting the effects of a healthy diet and provide a strong evidence to motivate people to change their eating habits. An open question about the quantity of food consumed may be a more effective way of determining the change in this area after the program.

The effects of dental hygiene on the participants were promising. Their skills in brushing their teeth improved significantly, and more participants acquired correct dental knowledge after four sessions of the dental program. This proves that dental health tends to be neglected among people with intellectual disabilities and that it is important to promote dental hygiene among this population to prevent dental problems or deterioration in the state of their teeth that might result in dental diseases.

There are some limitations in the study. Firstly, we encouraged a healthy lifestyle with active exercise and healthy diet for the residents living in the shelter home. Therefore, we invited all of the residents to participate into our program. The lacking of a control group limits the evidence of the effects of the program. A randomized controlled trial with involving experimental and control groups of similar age and physical condition, with more relevant measures to test people with intellectual disabilities might then be possible to better measure the positive effects of the program for adults with intellectual disabilities living in shelter homes. Secondly, there are lack of measures and questionnaires developed for assessing about physical functions or diet for adults with intellectual disabilities. Self-designed questionnaires were used in the study without reliability and validity measures for people with intellectual disabilities. With the importance of develop health program for the adults with intellectual disabilities but non-significant findings of this pilot study, we suggested further studies on establishing reliable and valid measures besides of conducting intervention and program for health promotion on this population.

\section{Conclusion}

This is the first study to investigate the effects of a program integrating physical exercise, a healthy diet, and dental hygiene for people with intellectual disabilities living in a shelter home. The participants were satisfied with the program and practiced the exercises and dental care skills that were capable for them to do at the shelter home. The participants spent more time exercising and showed some clinical improvement in physical functions after the program. Their dental hygiene and care was also improved significantly. However, no significant change was seen in their body composition and eating habits.

\section{References}

1. Elmahgoub SM, Lambers S, Stegen S, Van Laethem C, Cambier D, et al. (2009) The influence of combined exercise training on indices of obesity, physical fitness and lipid profile in overweight and obese adolescents with mental retardation. Eur J Pediatr 168: 1327-33.

2. Robertson J, Emerson E, Gregory N, Hatton C, Turner S, et al. (2000) Lifestyle related risk factors for poor health in residential settings for people with intellectual disabilities. Res Dev Disable 21: 469-86.

3. Temple VA, Walkley JW (2007) Perspectives of constraining and enabling factors for health-promoting physical activity by adults with intellectual disability. J Intellect Dev Disabil 32: 28-38.

4. Penedo FJ, Jason R (2005) Exercise and well-being: a review of mental and physical health benefits associated with physical activity. Curr Opin Psychiatry 18: 189-93.

5. Ekeland E, Heian F, Hagen KB, Abbott JM, Nordheirm L (2004) Exercise to improve self-esteem in children and young people. Cochrane Database of Sys Rev 1: $1-37$.

6. Saxena S, Van Ommeren M, Tang KC, Armstrong TP (2005) Mental health benefits of physical activity. J Ment Health 14: 445-51.

7. Draheim CC, Stanish HI, Williams DP, McCubbin JA (2007) Dietary intake of adults with mental retardation who reside in community settings. Am J Ment Retard 112: 392-400.

8. Humphries K, TraciMA, Seekins T (2009) Nutrition and adults with intellectual or developmental disabilities: systematic literature review result. Intellect Dev Disabil 47: 163-85.

9. World Cancer Research Fund and American Cancer Institute (1997) Food, Nutrition and the Prevention of Cancer: a Global Perspective. London:WCRF/AIC.

10. World Health Organization (2004) Global Strategy on Diet, Physical activity and Health. The 57th World Health Assembly.

11. British Society for Disability and Oral Health (2000) Guidelines for oral health care for people with a physical disability. London.

12. Kumar S, Sharma J, Duraiswamy P, Kulkani (2009) Determinants for oral hygiene and periodontal status among mental disabled children and adolescents. J Indian Soc Pedod Prev Dent 27: 151-7.

13. Ideal BMI Disease Prevention Project (in Chinese). Hospital Authority Health InfoWorld. Retrieved 2013-11-12.

14. Ross R, Berentzen T, Bradshaw AJ, Janssen I, Kahn HS, et al. (2008) Does the relationship between waist circumference, morbidity and mortality depend on measurement protocol for waist circumference? Obes Rev 9: 312-25.

15. World Health Organization (2008) Waist circumference and waist-hip ration: report of a WHO expert consultation, Geneva, Switzerland 8-11. 
16. Steffen TM, Hacker TA, Mollinger L (2002) Age- and gender- related test performance in community-dwelling elderly people: six-minute walk test, Berg Balance Scale, Timed Up \& Go test and gait speeds. Phys Ther 82: 128-37.

17. Lin MR, Hwang HF, Hu MH, Wu HDI, Wang YW, et al. (2004) Psychometric comparisons of the Timed Up and Go, one-leg stand, functional reach, and Tinetti Balance Measures in community-dwelling older people. J Am Geriatr Soc 52: 1343-8.

18. Whitney SL, Wrisley DM, Marchetti GF, Gee MA, Redfern MS, et al. (2005) Clinical measurement of Sit-to-Standperformance in people with balance disorders: validity of data for the Five-Times-Sit-To-Stand Test. Phys Ther 85: 1034-45.

19. Horner RD, Keilitz I (1975) Training mentally retarded adolescents to brush their teeth. J Appl Behav Anal 8: $301-9$.

20. Watts K, Jones TW, Davis EA, Green D (2005) Exercise training in obese children and adolescents: current concepts. Sports Med 35: 375-92.

21. Van Schrojenstein Lantman-De Valk HM, Metsemakers JF, Haveman MJ, Crebolder HF (2000) Health problems in people with intellectual disability in general practice: a comparative study. Fam Pract 17: 405-7.

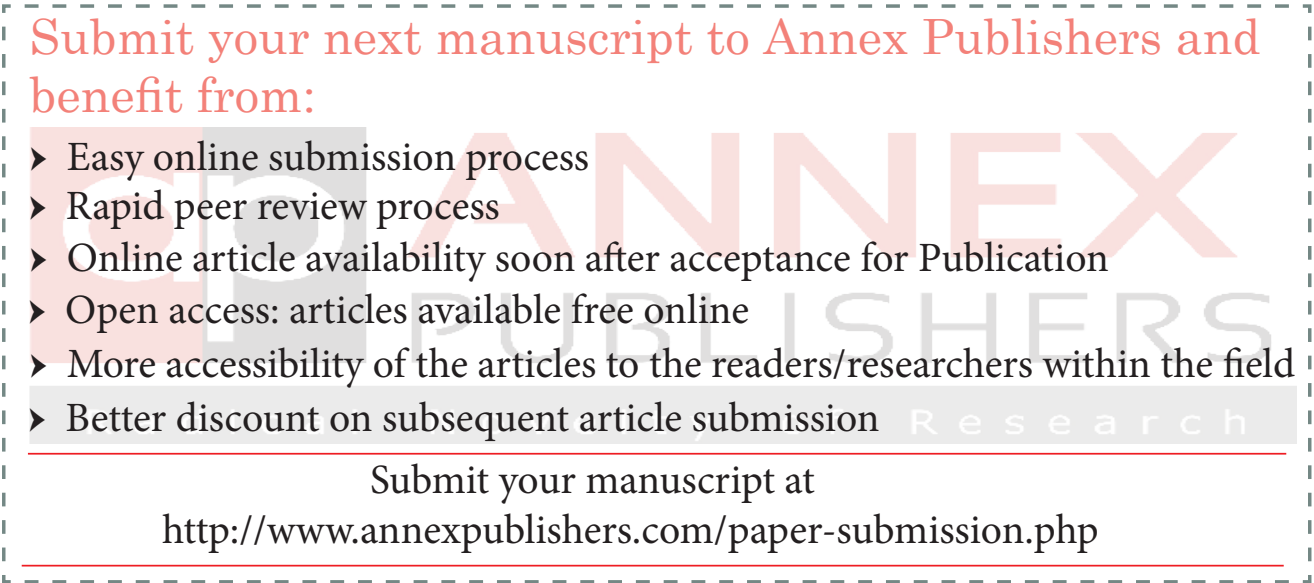

